\title{
Amount and duration of attentional demands during visual search
}

\author{
DAVID J. MADDEN and PHILIP A. ALLEN \\ Duke University Medical Center, Durham, North Carolina
}

\begin{abstract}
Previous research has suggested that, in visual-search tasks, the comparison between target and display items does not require attentional capacity. In the present experiment we used a secondary-task paradigm to distinguish the amount and duration of the attentional demands of visual search. The subjects performed visual search (the primary task) and tone detection (the secondary task) concurrently over the course of five experimental sessions $(1,440$ trials). For each subject, target-response mapping was either consistent or varied for Days 1-5. The results indicate that the amount of attentional demand, as reflected in secondary-task performance, increased as a function of display size in the search task. Switching from consistent to varied mapping in a sixth experimental session increased both the amount and the duration of the attentional demands of the search. The present results support models of visual-search performance in which the comparison of target and display items requires attentional capacity.
\end{abstract}

One of the most prominent characteristics of visualsearch performance is the influence of the number of items in the display on reaction time (RT) and error rate. Typically, visual search becomes slower and less accurate as the number of display items increases. As Logan (1976, 1978) has pointed out, however, this display-size effect is an empirical finding that is compatible with alternative theories of visual-search performance. The display-size effect may represent the involvement of limited attentional capacity in the comparison between target and display items (Atkinson, Holmgren, \& Juola, 1969; Rumelhart, 1970). Alternatively, the processing of display items may not require attentional capacity, but may involve a decision component with noise level being a function of display size (Estes, 1972; Gardner, 1973).

Although the display-size effect alone is not sufficient to distinguish these different interpretations of visualsearch performance, relevant evidence can be obtained from dual-task versions of visual search, in which search and some other task are performed concurrently. Dualtask methodology assumes that concurrent tasks compete for one or more pools of limited attentional capacity (i.e., processing resources); attentional demands are consequently revealed in the comparison between dual-task and single-task levels of performance (Wickens, 1984). One example of dual-task methodology is the secondary-task paradigm, in which subjects are instructed to devote most of their attention to one of the tasks (the primary task) and to perform the other (secondary) task with whatever

This research was supported by Research Grant AG02163, and Postdoctoral Training Grant AG00029, from the National Institute on Aging. We are grateful to Tina Caldwell and Marti Wilson for technical assistance. Correspondence regarding this article should be addressed to David J. Madden, Box 2980, Duke University Medical Center, Durham, NC 27710. "reserve" attention is available. Under ideal conditions (i.e., the two tasks do not require the same sensory-motor systems and primary-task performance is not disrupted by the addition of the secondary task), changes in secondary-task performance reflect the attentional capacity demands of the primary task (Duncan, 1980; Kantowitz, 1985; Kerr, 1973).

Logan (1978) proposed that the secondary-task paradigm can provide information regarding both the amount and duration of the attentional demands of visual search. In that study, Logan used a two-choice version of visual search as the primary task and simple RT to a tone as the secondary task. The temporal location of the tone relative to the visual display varied from $\mathbf{4 0 0} \mathrm{msec}$ preceding display onset to $600 \mathrm{msec}$ following display onset. RT could thus be plotted as a function of the stimulus-onset asynchrony (SOA) between the tone and the display. Logan found that the peak of the SOA curve (i.e., highest tone-RT value) was equivalent for displays of 4,8 , and 12 letters, whereas the breadth of the curve (i.e., its extension along the SOA axis) increased as a function of display size. Logan concluded that the duration of the attentional demands of search increased as display size increased, but that the magnitude of these demands (i.e., attentional allocation at a particular point in time) was independent of display size.

In Logan's (1978) model of visual search, display items were compared in parallel without capacity limitations. The effect of display size on the breadth of the SOA curve represented the duration of a "bookkeeping" operation for determining which display item was to be processed next. It was this bookkeeping operation, rather than comparison per se, that was attention-demanding.

Madden (1986) also used a secondary-task version of visual search in which the primary task required a twochoice response to a visual display and the secondary task 
was tone detection. In Madden's study, display size was either two or four letters, and the SOA between the tone and the display varied from $-400 \mathrm{msec}$ (i.e., tone preceding display) to $700 \mathrm{msec}$. In contrast to Logan (1978), however, Madden found that the height as well as the breadth of the SOA curve for tone RT increased significantly as a function of display size. Madden's results consequently suggest that the comparison of the target and display items was capacity-limited. In addition, the Madden (1986) data demonstrated that the increase in the height of the SOA curve as a function of display size was present in the performance of a group of older adults (in their $60 \mathrm{~s}$ and $70 \mathrm{~s}$ ) as well as in the performance of collegeage subjects.

One difference in the methodology of the secondarytask search paradigms reported by Logan (1978) and Madden (1986) is that in the former study, the target letters were consistently mapped to responses, whereas in the latter study, varied mapping was used. In each experiment, one target letter was assigned to each of two response keys, and one target was present in each display. In the Logan study, the targets were always $A$ and $\mathrm{V}$. The Madden experiment assigned two new targets at the beginning of each trial block and used the targets from one trial block as distractors in other blocks. Another difference in the two studies is that the subjects in the Logan experiment performed a total of 576 trials, whereas the subjects in the Madden experiment performed 288 trials.

Substantial evidence has accumulated to indicate that training with consistent mapping can play a major role in reducing the attentional demands of search tasks (Schneider, Dumais, \& Shiffrin, 1984; Schneider \& Fisk, 1982). Thus, Logan's (1978) unlimited-capacity model may hold only under consistent-mapping conditions. To examine this possibility, in the present experiment we compared the effects of varied and consistent mapping over the course of moderate training (1,440 trials) in a secondary-task version of visual search. The question of central concern was the potential change, as a function of stimulus-response mapping and display size, in the shape of the curve relating secondary-task RT to SOA. If the use of consistent, as opposed to varied, mapping was responsible for the different pattern of results obtained by Logan (1978) and Madden (1986), then the height of the SOA curve should be greater in the varied-mapping condition than in the consistent-mapping condition, especially as display size increases. As an additional test of the influence of stimulus-response mapping, all subjects in the consistent-mapping condition of the present experiment were switched to varied mapping in the final testing session.

\section{METHOD}

\section{Subjects}

Twenty Duke University students and employees between 19 and 32 years of age ( $M=21.5$ years) participated. There were 10 subjects (5 of each gender) in each of the two stimulus-response mapping conditions. All subjects reported normal or corrected vision and were paid to complete six 1-h sessions, performed on separate days. The mean raw scores on the Vocabulary subtest of the Wechsler Adult Intelligence Scale (WAIS) were equivalent for subjects in the varied-mapping condition (65.60) and for those in the consistent-mapping condition (64.20). Similarly, the two groups were equivalent in their mean raw scores on the Digit Symbol Substitution subtest of the WAIS (74.20 and 77.30 for the varied- and consistent-mapping conditions, respectively).

\section{Apparatus and Stimuli}

The presentation of the stimuli and the measurement of subjects' responses were controlled by an Apple Ile microcomputer containing a Mountain Hardware clock card. The visual displays were presented on an NEC video monitor that used a P31 green phosphor. Each character space on the monitor screen was $0.56^{\circ}$ wide $\times 0.85^{\circ}$ high at a viewing distance of $40 \mathrm{~cm}$. The luminance of the characters was $12 \mathrm{~cd} / \mathrm{m}^{2}$ against a $4 \mathrm{~cd} / \mathrm{m}^{2}$ background. Normal room illumination was provided by overhead fluorescent lamps. The tone used as a stimulus in the secondary task was a 213-msec tone generated by the microcomputer and presented via a loudspeaker internal to the microcomputer at approximately $60 \mathrm{~dB}$. Response keys were located on the microcomputer keyboard. The subjects made their responses to the visual display with the index and middle fingers of their dominant hands. Responses to the tone were made with the index finger of their nondominant hands.

For both the consistent and the varied stimulus-response mapping conditions, the primary task was a two-choice version of visual search and the secondary task was simple RT to a tone. A memoryset of two target letters was assigned at the beginning of each trialblock, and one of these letters occurred in the visual display that was presented on each trial. The subjects pressed one of the two primary-task response keys depending on which of the targets was present in the display. On each day, the subjects performed one block of practice trials and five blocks of test trials in which the primary and secondary tasks were combined. In the varied-mapping condition, the five target pairs $\mathrm{L}-\mathrm{B}, \mathrm{S}-\mathrm{V}, \mathrm{T}-\mathrm{Q}, \mathrm{J}-\mathrm{Z}$, and $\mathrm{N}-\mathrm{D}$ were used in the five test-trial blocks; F-G was always the target set in the practice block. Within each block of trials in the varied-mapping condition, the 10 letters that were not currently being used as targets, plus the letters $H$ and $P$, were used as nontarget (i.e., distractor) items in the displays. In the consistent-mapping condition, $F$ and $G$ were always the targets, and the 10 other targets from the varied-mapping condition, plus $H$ and $P$, were the distractors.

The visual display presented on each trial contained one target letter and either one or three distractor letters. Individual letters were not repeated within a display. The letters were arranged at the corner of an imaginary grid that had three character spaces per side. There were two forms of two-item displays, which were used equally in each trial block. In one form, the display letters were located in the upper-left and lower-right display positions, and in the other form, the two letters were located in the upper-right and lower-left display positions. The positions in the two-item displays that did not contain letters were blank.

Each trial block contained a randomized sequence of 48 trials32 tone-present trials in which both a tone and a visual display were presented, and 16 tone-absent trials in which only a visual display was presented. In the tone-present trials, the onset of the tone either preceded the onset of the display by $400 \mathrm{msec}$ or followed the onset of the display by 100,400 , or $700 \mathrm{msec}$. In each trial block, there were four trials for each combination of display size and SOA in the 32 tone-present trials. The 16 tone-absent trials within each block contained eight trials for each display size. In each block, each of the current targets appeared in the display a total of 16 times in the tone-present trials, eight times at each display size. These eight occurrences contained two trials for each SOA value and two for each position within the display, but the relation between the SOA and display position was random for individual targets. Within each block, the 12 current distractor letters each appeared four times 
in the tone-present trials that contained four-item displays, once at each display position. Each occurrence was associated with a different SOA value. Each of the distractors appeared twice in the tone-present trials that contained two-item displays; each occurrence was at a different display position and SOA value. Each of the current targets appeared eight times per block in the tone-absent trials, once for each combination of display size and position in the display. Each of the 12 distractors appeared twice per block in the tone-absent trials that contained four-item displays, with each occurrence at a different display position. In the eight tone-absent trials that contained two-item displays, eight different distractor letters were used as the nontarget display item.

\section{Procedure}

The subjects were instructed to consider the visual-search task as their primary task (i.e., to devote most of their attention to it) and to "protect" their search performance if they encountered interference on the dual-task trials. For both tasks, the subjects were instructed to respond as quickly as possible while still being correct. At the beginning and end of each experimental session, the subjects performed a block of 30 baseline simple-RT trials in which only the tone was presented. As was the case for the dual-task test trials, the subjects pressed a response key to each tone with the index finger of their nondominant hands. At the offset of each tone in the baseline trials, the microcomputer randomly selected a waiting period of 2 to $4 \mathrm{sec}$ (in 200-msec steps) before presenting the next tone. The mean of these 60 trials for a particular session represented the baseline simple-RT for that session. To reduce the potential influence of individual differences in tone-detection RT, the dependent variable in the analysis of secondary-task performance was formed by subtracting (for each subject) the baseline simpleRT for a particular session from the mean secondary-task tone-RT in each of the experimental conditions.

All subjects performed the first of the six sessions on a Friday and completed the subsequent sessions on the following Monday through Friday. The subjects in the varied-mapping condition received varied mapping on all six days, whereas the subjects in the consistent-mapping condition received consistent mapping on Days 1-5 and varied mapping on Day 6. For each mapping condition, five orders of the test-trial blocks for Days 1-5 were arranged in a Latin square, and 2 subjects ( 1 of each gender) were assigned to each order. The subjects in both mapping conditions received the same five varied-mapping test blocks on Day 6. Thus, the subjects who switched from consistent to varied mapping across Days 5 and 6 used the distractor letters from Days 1-5 as targets on Day 6 .
For each subject, the particular block order that was used on Day 1 was also used on Day 6.

A message assigning each of the current target letters to one of the two response keys for the search task was displayed at the top of the viewing screen between each trial. The subjects initiated a trial by pressing the space bar on the keyboard, which erased the target/response message and presented a warning signal (a cursor) in the center of the viewing screen for $1 \mathrm{sec}$. The visual display appeared $500 \mathrm{msec}$ after the offset of the cursor, and the letters in the display were centered around the character space at which the cursor had appeared. Responses to both the display and the tone were measured from the onset of each stimulus. The display remained on the screen until one of the visual-response keys was pressed.

\section{RESULTS}

\section{Days 1-5}

Visual search. The RT data for Days 1-5 of the visualsearch task are presented in Figure 1. An analysis of variance (ANOVA) was performed on subjects' mean RTs in which stimulus-response mapping (varied or consistent) was a between-subjects variable. Display size (two or four letters), day (1-5), and the presence versus the absence of the tone were within-subjects variables. This ANOVA yielded significant main effects of display size $[F(1,18)=$ $263.49, p<.0001]$, day $[F(4,72)=9.52, p<.0001]$, and tone presence $[F(1,18)=5.68, p<.05]$. Search $\mathrm{RT}$ was slower for four-item displays $(627 \mathrm{msec})$ than for two-item displays $(538 \mathrm{msec})$, slower for tone-present displays $(588 \mathrm{msec})$ than for tone-absent displays (576 $\mathrm{msec}$ ), and became shorter across successive days $(631,585,582,560$, and $552 \mathrm{msec}$ for Days 1-5, respectively).

The interactions of display size $\times$ mapping, $[F(1,18)$ $=9.09, p<.01]$, display size $\times$ day $[F(4,72)=4.24$, $p<.01]$, display size $\times$ tone presence $[F(1,18)=6.91$, $p<.05]$, and mapping $\times$ tone presence $[F(1,18)=9.90$, $p<.01]$ were also significant. The display size $\times$ mapping effect represented a larger display-size effect (i.e., RT for four-item displays minus RT for two-item displays)

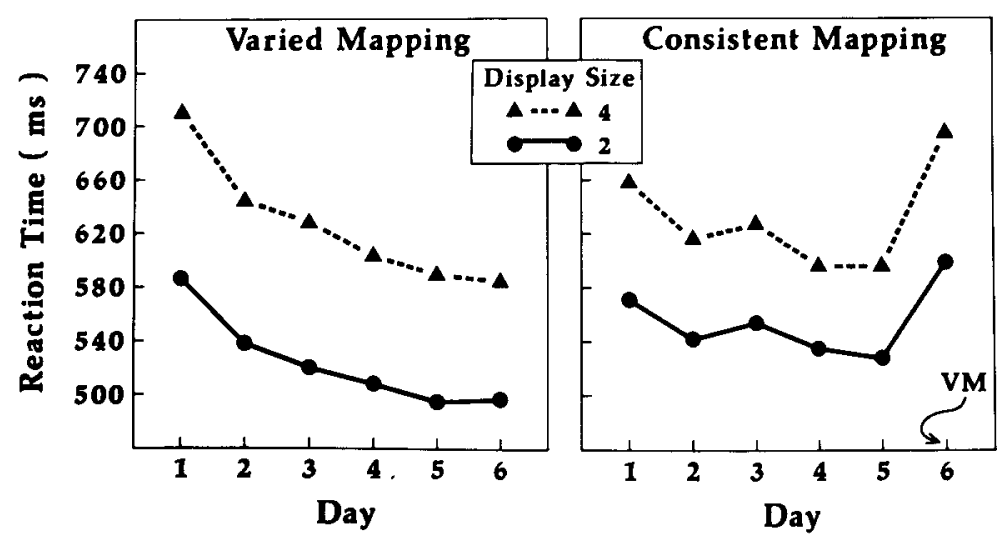

Figure 1. Mean reaction time in the visual-search task as a function of mapping condition, display size, and day. On Day 6, the subjects in the consistent-mapping condition were switched to a varied-mapping version of the search task. 
in the varied-mapping condition (106 $\mathrm{msec})$ than in the consistent-mapping condition $(72 \mathrm{msec})$. The simple main effect of display size was significant within each mapping condition $[F>84.0$ in each case], but the simple main effect of mapping was not significant at either display size. The display size $x$ day interaction occurred because the display-size effect was greater on Day $1(106 \mathrm{msec})$ than on Days 2-5 $(90,90,78$, and $81 \mathrm{msec}$, respectively). The display size $\times$ day interaction was not significant when the Day-1 data were excluded from the analysis. The display size $X$ tone presence effect represented a greater increase in search RT on tone-present trials, relative to toneabsent trials, for four-item displays $(16 \mathrm{msec})$ than for two-item displays $(6 \mathrm{msec})$. Similarly, the mapping $x$ tone presence effect was the result of a 26-msec RT increase associated with the presence of the tone in the varied-mapping condition, whereas RT was actually $4 \mathrm{msec}$ slower on tone-absent trials than on tone-present trials in the consistent-mapping condition.

The mean percentage of errors in the visual-search task across Days 1-5 was 1.78 in the consistent-mapping condition and 2.15 in the varied-mapping condition.

Tone detection. Mean simple RT on the baseline (toneonly) trials was $197 \mathrm{msec}$ in the varied-mapping condition and $211 \mathrm{msec}$ in the consistent-mapping condition. An ANOVA performed on mean baseline RT, using mapping condition and day as independent variables, did not yield any significant effects.

The dependent variable in the analysis of secondarytask performance was tone RT in each of the dual-task conditions minus simple RT from the baseline trials. The mean values for this measure are presented in Figures 2 and 3. The ANOVA of the tone-RT measure used mapping condition as a between-subjects variable; display size, day, and the SOA between the tone and the display $(-400$,
$100,400,700 \mathrm{msec}$ ) were within-subjects variables. This ANOVA yielded significant main effects of display size $[F(1,18)=99.61, p<.0001]$, day $[F(4,72)=10.23$, $p<.0001]$, and SOA $[F(3,54)=38.64, p<.0001]$. These effects represented, respectively, a slower tone RT for four-item displays ( $323 \mathrm{msec}$ ) relative to two-item displays ( $284 \mathrm{msec}$ ); a decrease in tone RT from $360 \mathrm{msec}$ on Day 1 to $304,289,289$, and $275 \mathrm{msec}$ on successive days; and a change in tone RT from $392 \mathrm{msec}$ at the $-400 \mathrm{msec}$ SOA to 448,221 , and $152 \mathrm{msec}$ at the successive SOAs.

The interactions of display size $\times$ mapping $[F(1,18)$ $=14.36, p<.001]$, display size $\times \operatorname{SOA}[F(3,54)=$ $39.28, p<.0001]$, and display size $\times$ Day $\times$ SOA $[F(12,216)=1.99, p<.05]$ were also significant. The display size $\times$ mapping effect occurred because the increase in tone RT for the four-item displays, relative to the two-item displays, was greater in the varied-mapping condition ( $54 \mathrm{msec}$ ) than in the consistent-mapping condition ( $24 \mathrm{msec}$ ). The simple main effect of display size was significant within each mapping condition $[F>27.0$ in each case]. The simple main effect of mapping, however, was not significant for either display size.

The display size $\times$ SOA and display size $\times$ day $\times$ SOA effects represented changes, as a function of display size and day, in the shape of the curve relating tone RT to the four SOA values. The three-way interaction was not significant when Day 1 was excluded from the data, whereas the display size $\times$ SOA effect was significant both for Day 1 considered alone and for Days 2-5 $[F>9.0$ in each case]. The SOA data are presented for Day 1 and for Days 2-5 separately in Table 1. Comparisons of pairs of SOA means were made with post hoc $t$ tests using the Sidak inequality for controlling the experimentwise error rate (Games, 1977). For the two-item

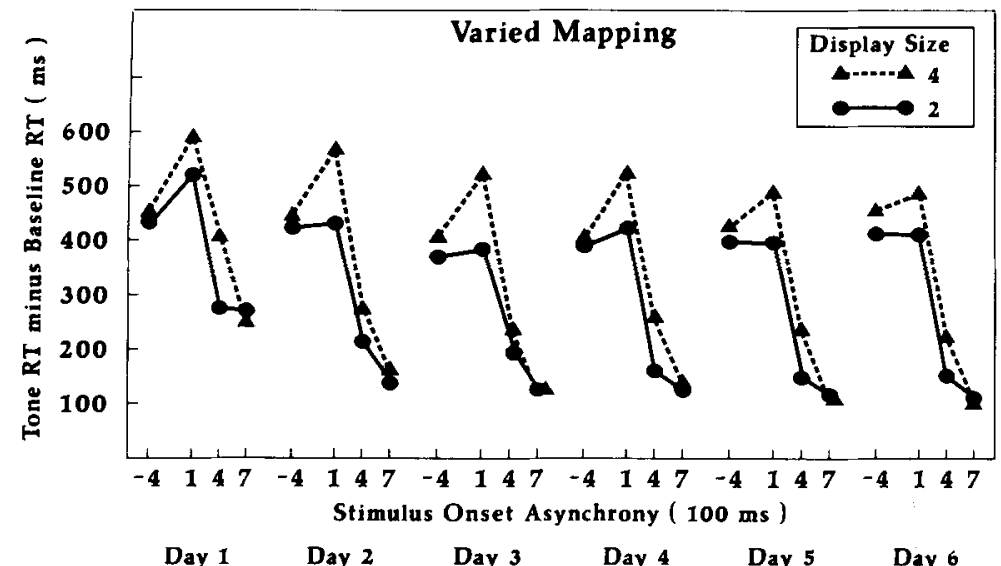

Figure 2. Mean reaction time in the tone-detection task (minus baseline tone-reaction time) in the varied mapping condition as a function of display size, day, and the stimulus-onset asynchrony between the tone and the visual display. The onset of the tone occurred either 400 msec before the onset of the display $(-4)$ or $100(1), 400$ (4), or 700 msec (7) following the onset of the display. The subjects performed varied mapping on all six days. 


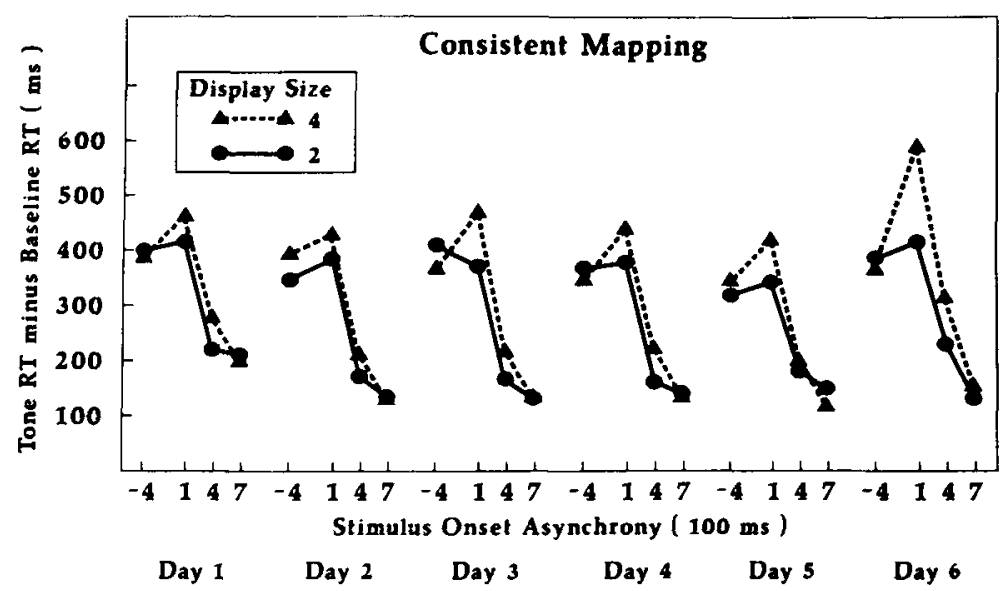

Figure 3. Mean reaction time in the tone-detection task (minus beseline tone-reaction time) in the consistent-mapping condition as a function of display size, day, and the stimulus-onset asynchrony between the tone and the visual display. The onset of the tone occurred either 400 msec before the onset of the display (-4) or 100 (1), 400 (4), or 700 msec (7) following the onset of the display. The subjects performed consistent mapping on Days 1-5 and varied mapping on Day 6.

displays on Day 1, the increase in tone RT from the -400 msec SOA to the 100-msec SOA was not significant, although the decrease in tone RT from this latter SOA to the 400-msec SOA was significant. For these displays, tone RT at both the 400 - and the 700 -msec SOA was significantly faster than at the $-400-\mathrm{msec}$ SOA. For the fouritem displays on Day 1 , both the increase from the -400 msec SOA to the 100 -msec SOA, and the decrease from this latter point to the 400 -msec SOA, were significant. Tone RT for these displays, however, did not decrease significantly below the -400 -msec SOA level until $700 \mathrm{msec}$ following display onset. On Day 1, the peak of the SOA curve for both display sizes occurred at the 100-msec SOA; tone RT at this SOA was significantly slower for the four-item displays $(525 \mathrm{msec})$ than for

Table 1

Mean Reaction Time in the Tone-Detection Task as a Function of Day, Display Size, and the Stimulus-Onset Asynchrony Between the Tone and the Display

\begin{tabular}{|c|c|c|c|c|}
\hline \multirow[b]{2}{*}{ Display Size } & \multicolumn{4}{|c|}{ Stimulus-Onset Asynchrony (msec) } \\
\hline & -400 & 100 & 400 & 700 \\
\hline \multicolumn{5}{|c|}{ Day 1} \\
\hline 2 letters & 416 & 468 & 248 & 241 \\
\hline 4 letters & 419 & 525 & 342 & 224 \\
\hline \multicolumn{5}{|c|}{ Days 2-5 } \\
\hline 2 letters & 378 & 389 & 175 & 134 \\
\hline 4 letters & 393 & 483 & 231 & 130 \\
\hline
\end{tabular}

Note- Reaction-time (RT) values represent mean tone RT on the dualtask trials minus baseline RT on the tone-only trials. For Day 1, the minimum significant difference required by the Sidak $t$ test $(\alpha=.05)$, for pairs of SOA means, was $106 \mathrm{msec}$ for two-item displays and $104 \mathrm{msec}$ for four-item displays. For Days 2-5, the minimum significant difference between pairs of SOA means was $82 \mathrm{msec}$ for two-item displays and $93 \mathrm{msec}$ for four-item displays. the two-item displays [468 $\mathrm{msec}, F(1,18)=10.40$, $p<.01]$.

For the two-item displays on Days 2-5, the pattern of change in mean tone RT across SOA was identical to the corresponding pattern on Day 1. For the four-item displays on Days 2-5, however, the increase in tone RT between the -400 - and the 100 -msec SOAs was not significant, and by $400 \mathrm{msec}$ after display onset, tone RT was significantly faster than at the $-400 \mathrm{msec}$ SOA. As on Day 1, the peak of the SOA curve for Days 2-5 was located at the $100 \mathrm{msec}$ SOA, and tone RT at this SOA was significantly slower for four-item displays (483 msec) than for two-item displays $[389 \mathrm{msec}, F(1,18)=128.14$, $p<.0001]$.

Across Days 1-5, the mean percentage of failures to respond to the tone (i.e., misses) was less than 1.0 in each mapping condition. The mean percentage of false-alarm responses on tone-absent trials was 2.08 in the variedmapping condition and 2.30 in the consistent-mapping condition.

Interaction of visual-search and tone-detection tasks. The effects of tone presence in the visual-search data suggest that the subjects were not able to perform the visualsearch and tone-detection tasks completely independently. To examine the performance interaction between the two tasks further, visual-search RT on the tone-present trials was examined as a function of SOA. The mean search RTs for each combination of mapping condition, day, display size, and SOA are presented in Table 2. An ANOVA of the data from Days 1-5 did not yield a significant main effect of SOA, but the interactions of SOA $\times$ mapping condition $[F(3,54)=10.98, p<.0001]$, SOA $\times$ day $[F(12,216)=3.0, p<.001]$, and SOA $\times$ display size $\times$ mapping condition $[F(3,54)=3.38, p<.05]$ were significant. These interactions represented primarily an 
Table 2

Mean Reaction Time (RT) on the Tone-Present Trials in the Visual-Search Task and Mean Interresponse Interval (IRI) Between the Visual and Tone Responses as a Function of Day, Display Size, Mapping Condition, and the Stimulus-Onset Asynchrony Between the Tone and the Display

\begin{tabular}{|c|c|c|c|c|c|c|c|c|c|c|c|c|c|}
\hline \multirow{2}{*}{$\begin{array}{c}\text { Stimulus Onset } \\
\text { Asynchrony (msec) }\end{array}$} & \multirow{2}{*}{$\begin{array}{l}\text { Display } \\
\text { Size }\end{array}$} & \multicolumn{2}{|c|}{ Day 1} & \multicolumn{2}{|c|}{ Day 2} & \multicolumn{2}{|c|}{ Day 3} & \multicolumn{2}{|c|}{ Day 4} & \multicolumn{2}{|c|}{ Day 5} & \multicolumn{2}{|c|}{ Day 6} \\
\hline & & RT & $\overline{\text { IRI }}$ & $\overline{\mathrm{RT}}$ & $\overline{\text { IRI }}$ & $\overline{\mathrm{RT}}$ & $\overline{\text { IRI }}$ & $\overline{\mathrm{RT}}$ & IRI & RT & $\overline{\text { IRI }}$ & RT & IRI \\
\hline \multicolumn{14}{|c|}{ Varied Mapping } \\
\hline \multirow[t]{2}{*}{-400} & 2 & 675 & -644 & 604 & -581 & 563 & -594 & 542 & -552 & 525 & -527 & 524 & -512 \\
\hline & 4 & 805 & -753 & 734 & -687 & 691 & -685 & 665 & -659 & 625 & -599 & 639 & -585 \\
\hline \multirow[t]{2}{*}{100} & 2 & 589 & 31 & 535 & -3 & 504 & -20 & 511 & 12 & 485 & 11 & 496 & 15 \\
\hline & 4 & 728 & -40 & 667 & 0 & 628 & -5 & 617 & 6 & 608 & -19 & 586 & 1 \\
\hline \multirow[t]{2}{*}{400} & 2 & 562 & 113 & 540 & 74 & 519 & 75 & 495 & 65 & 488 & 60 & 487 & 65 \\
\hline & 4 & 721 & 85 & 627 & 47 & 610 & 25 & 602 & 56 & 608 & 27 & 582 & 40 \\
\hline \multirow[t]{2}{*}{700} & 2 & 559 & 412 & 543 & 295 & 525 & 301 & 517 & 308 & 495 & 321 & 492 & 320 \\
\hline & 4 & 672 & 277 & 631 & 231 & 623 & 201 & 591 & 248 & 583 & 225 & 573 & 227 \\
\hline \multicolumn{14}{|c|}{ Consistent Mapping } \\
\hline \multirow[t]{2}{*}{-400} & 2 & 599 & -599 & 515 & -568 & 558 & -570 & 522 & -553 & 488 & -570 & 615 & -627 \\
\hline & 4 & 651 & -663 & 585 & -592 & 594 & -606 & 562 & -612 & 560 & -609 & 739 & -773 \\
\hline \multirow[t]{2}{*}{100} & 2 & 582 & -65 & 549 & -64 & 536 & -50 & 514 & -36 & 532 & -89 & 575 & -59 \\
\hline & 4 & 678 & -116 & 616 & -88 & 606 & -53 & 586 & -43 & 587 & -68 & 738 & -48 \\
\hline \multirow[t]{2}{*}{400} & 2 & 558 & 64 & 542 & 30 & 553 & 13 & 521 & 39 & 532 & 49 & 596 & 34 \\
\hline & 4 & 687 & -8 & 611 & 0 & 624 & -8 & 612 & 10 & 598 & 2 & 716 & -1 \\
\hline \multirow[t]{2}{*}{700} & 2 & 563 & 347 & 551 & 284 & 546 & 292 & 541 & 305 & 560 & 290 & 582 & 250 \\
\hline & 4 & 675 & 223 & 620 & 209 & 649 & 179 & 625 & 202 & 625 & 193 & 691 & 163 \\
\hline
\end{tabular}

Note-Values are in milliseconds. Interresponse interval $=$ tone RT + SOA - search RT.

increase in search RT at the -400 -msec SOA relative to the other SOAs, especially in the varied-mapping condition and on Day 1. The simple main effect of SOA was significant for the varied-mapping condition $[F(3,27)=$ $9.47, p<.001]$, but not for the consistent-mapping condition. The simple main effect of SOA was significant on Day $1[F(3,54)=6.15, p<.001]$, but not on any of the subsequent days. The SOA $\times$ display size interaction was not significant for either mapping condition considered separately.

The interaction of visual-search and tone-detection performance was also examined in an analysis of interresponse interval (IRI), defined by the equation IRI = tone RT + SOA - search RT. Previous analyses of dualtask performance have led to the proposal that, when subjects are able to perform the primary and secondary tasks independently, the function relating IRI to SOA is linear and possesses a slope of 1.0 (Kahneman, 1973, chap. 9; Logan, 1978). Interaction between the tasks, in contrast, leads to a constancy of IRI across SOA. Thus, in the present data, interaction between the tasks would be represented by an IRI function that either possesses a slope of zero or is increasing but nonlinear, with a local flattening of the function in the SOA region of greatest interference.

Interresponse intervals were computed for each subject, and the mean IRI values are presented in Table 2 . For Days 1-5, the increase in IRI across SOA revealed significant linear $[F(1,18)=326.56, p<.0001]$, quadratic $[F(1,18)=54.54, p<.0001]$, and cubic $[F(1,18)=$ $219.49, p<.0001]$ trends. The linear component, however, accounted for $88 \%$ of the variance associated with the SOA effect, whereas the quadratic and cubic trends accounted for $7 \%$ and $5 \%$, respectively. The slope of the function relating IRI to SOA on Days $1-5$ was 0.80 in the varied-mapping condition and 0.75 in the consistentmapping condition.

\section{Days 5-6}

The effects of switching from consistent to varied mapping on Day 6 were examined by analyses of both the visual-search and tone-detection data on Days 5 and 6. In these analyses, the between-subjects variable of mapping refers to the subjects' condition on Day 5.

Visual search. The ANOVA of the visual-search RT data for Days 5 and 6 yielded significant main effects of display size $[F(1,18)=384.40, p<.0001]$ and tone presence $[F(1,18)=5.60, p<.05]$ that were consistent with the corresponding effects on Days $1-5$. The displaysize effect was $86 \mathrm{msec}$ and the tone-presence effect was $12 \mathrm{msec}$. The main effect of day $[F(1,18)=7.56$, $p<.01]$ represented a $41-\mathrm{msec}$ increase in search RT from Day 5 to Day 6. In addition, the ANOVA of the search RTs for Days 5 and 6 yielded significant interactions for day $\times$ mapping $[F(1,18)=8.14, p<.01]$, tone presence $\times$ day $\times$ mapping $[F(1,18)=4.60, p<.05]$, and day $\times$ display size $\times$ mapping $[F(1,18)=4.96$, $p<.05]$.

The day $\times$ mapping and day $\times$ display size $\times$ mapping interactions represent changes in search RT across Days 5 and 6 as a function of mapping condition and display size. The simple main effect of day was not significant for either display size in the varied-mapping condition. In the consistent-mapping condition, the increase in search RT across days was significant for both display sizes $[F>5.0$ in each case], and the magnitude of the increase was greater for four-item displays ( $99 \mathrm{msec}$ ) than for two-item displays $(71 \mathrm{msec})$. As a result, the display- 
size effect in the consistent-mapping condition increased from $68 \mathrm{msec}$ on Day 5 to $96 \mathrm{msec}$ on Day 6 . The displaysize effect in the varied-mapping condition was $94 \mathrm{msec}$ on Day 5 and $88 \mathrm{msec}$ on Day 6. The simple main effect of mapping was not significant for either display size on Day 5. On Day 6, search RT was slower in the consistentmapping condition than in the varied-mapping condition by $103 \mathrm{msec}$ for the two-item displays, and by $111 \mathrm{msec}$ for the four-item displays $[F>6.0$ in each case].

The tone presence $\times$ day $\times$ mapping effect represents an increase in the tone-presence effect for the consistentmapping condition from $-4 \mathrm{msec}$ on Day 5 to $19 \mathrm{msec}$ on Day 6, whereas the tone-presence effect for the variedmapping condition was $20 \mathrm{msec}$ on Day-5 and $13 \mathrm{msec}$ on Day 6.

In the consistent-mapping condition, the mean percentage error in the visual-search task increased from 1.44 on Day 5 to 2.62 on Day 6. The mean error rates in the varied-mapping condition were $1.91 \%$ on Day 5 and $1.40 \%$ on Day 6.

Tone detection. Mean simple RT on the baseline trials was $190 \mathrm{msec}$ on Day 5 and $192 \mathrm{msec}$ on Day 6 in the varied-mapping condition. In the consistent-mapping condition, mean simple RT was $212 \mathrm{msec}$ on Day 5 and $205 \mathrm{msec}$ on Day 6. An ANOVA of these baseline simple RTs, as a function of day and mapping condition, did not yield any significant effects.

The dependent variable in the analysis of secondarytask performance was tone-RT in each of the dual-task conditions minus simple RT from the baseline trials. The mean values for this measure are presented in Figures 2 and 3. The ANOVA of dual-task tone-RT minus baseline tone-RT on Days 5 and 6 yielded main effects of display size $[F(1,18)=64.22, p<.0001]$ and SOA $[F(3,54)=$ $33.19, p<.0001]$ that were consistent with those obtained for Days 1-5. The tone-RT data also yielded significant interactions of day $\times$ mapping $[F(1,18)=7.92$, $p<.01]$, day $\times$ display size $\times$ mapping $[F(1,18)=$ $6.20, p<.05]$, display size $\times \operatorname{SOA}[F(3,54)=22.98$, $p<.0001]$, and day $\times$ display size $\times$ SOA $\times$ mapping $[F(3,54)=3.55, p<.05]$. The day $\times$ mapping and day $X$ display size $\times$ mapping effects represent changes in tone RT across Days 5 and 6 as a function of mapping condition and display size. In the varied-mapping condition, there was no significant change in tone RT between Days 5 and 6 for either display size. In the consistentmapping condition, tone RT for the two-item displays did not change significantly across days, whereas tone RT for the four-item displays exhibited an 84-msec increase that was significant $[F(1,9)=19.86, p<.01]$. Consequently, on Day 5, the display-size effect was relatively larger in the varied-mapping condition $(49 \mathrm{msec})$ than in the consistent-mapping condition ( $24 \mathrm{msec})$, whereas the reverse was true on Day 6 ( 44 and $64 \mathrm{msec}$ in the variedand consistent-mapping conditions, respectively). The simple main effect of mapping, however, was not significant for any combination of day and display size.

The interactions involving SOA represent changes in the shape of the SOA curve between Days 5 and 6. On
Day 5 , the display size $\times$ SOA interaction was significant $[F(3,54)=7.55, p<.001]$, but the display size $\times$ SOA $\times$ mapping interaction was not significant. The shape of the SOA curve for the two display sizes on Day 5 was the same as the pattern that was evident in the analysis of Days 2-5: although the absolute magnitude of the increase in tone RT between the -400 -msec SOA and the 100 -msec SOA was greater for four-item displays than for two-item displays, neither increase was significant by post hoc $t$ test, and by the $400-\mathrm{msec}$ SOA the tone RT for both display sizes had decreased to a level significantly below that of the -400 -msec SOA. On Day 5 , the peak of the SOA curve for both display sizes occurred at the 100 -msec SOA, and tone RT at this SOA was significantly longer for four-item displays (454 msec) than for twoitem displays $[370 \mathrm{msec}, F(1,18)=28.37, p<.0001]$.

On Day 6 , both the display size $\times$ SOA effect $[F(3,54)$ $=17.93, p<.0001]$ and the display size $\times$ SOA $\times$ mapping interaction $[F(3,54)=6.11, p<.001]$ were significant. The shapes of the SOA curves in the variedmapping condition on Day 6 were not significantly different from the pattern that was present on Days 2-5. For the two-item displays in the consistent-mapping condition on Day 6, the SOA curve also resembled the curve for Days 2-5. The four-item displays in the consistentmapping condition on Day 6, however, exhibited a significant increase in tone RT between the $-400 \mathrm{msec}$ SOA and the 100-msec SOA. In addition, for the four-item displays, tone RT did not decrease significantly below the level of the -400 -msec SOA until 700 msec after display onset. In each mapping condition on Day 6, tone RT at the 100-msec SOA was significantly slower for four-item displays than for two-item displays $[F>26.0$ in each case].

The miss rate in the tone-detection task remained below $1.0 \%$ for each mapping condition on both Day 5 and Day 6. The false-alarm rate for the varied-mapping condition was the same (2.75\%) on Days 5 and 6 . The falsealarm rate for the consistent-mapping condition was $2.63 \%$ on Day 5 and $4.25 \%$ on Day 6.

Interaction of visual-search and tone-detection tasks. In the ANOVA of visual-search RT on the tone-present trials for Days 5-6, the main effect of SOA was not significant, but the interactions of SOA $\times$ day $[F(3,54)=$ $13.62, p<.0001]$ and SOA $\times$ day $\times$ mapping condition $[F(3,54)=7.98, p<.001]$ were significant. The SOA $\times$ day interaction was not significant for the variedmapping condition considered separately, but was significant for the consistent-mapping condition $[F(3,27)=$ $15.31, p<.0001]$. In the consistent-mapping condition, the simple main effect of SOA was significant on Day 5 $[F(3,27)=4.97, p<.01]$, primarily as a result of the relatively faster $\mathrm{RT}$ at the $-400-\mathrm{msec}$ SOA. The consistent-mapping condition did not exhibit a significant SOA effect on Day 6.

In the analysis of the IRI values for Days 5-6, the increase in IRI across SOA was $89 \%$ linear on Day 5 and $85 \%$ linear on Day 6 . The slope of the IRI function for the varied-mapping condition was 0.73 on Day 5 and 0.72 
on Day 6. For the consistent-mapping condition, the slope was 0.74 on Day 5 and 0.81 on Day 6 .

\section{DISCUSSION}

\section{Primary-Task Performance}

The subjects' primary-task RTs were influenced by stimulus-response mapping in a manner consistent with previous findings. For Days $1-5$, the display size $\times$ mapping interaction in the search-RT data occurred because the effect of display size was greater in the variedmapping condition than in the consistent-mapping condition. This pattern confirms the results of previous experiments that measured RT to single displays, as well as of experiments that measured search accuracy for multipleframe displays, in which the effects of processing load were more pronounced in varied-mapping conditions than in consistent-mapping conditions (Schneider et al., 1984).

In the present experiment, however, the simple main effect of display size was significant even within the consistent-mapping condition, and the interaction of display size and mapping did not vary significantly across Days 1-5. Although there was a slight decrease, averaged across mapping condition, in the magnitude of the displaysize effect across Days 1-5, this pattern was due primarily to the relatively larger display-size effect on Day 1 than on the succeeding days. In the present experiment, consistent mapping was associated with a reduction in the magnitude of the display-size effect but not with an elimination of the effect, and the influence of consistent mapping did not increase over the first five sessions. There was also a significant effect of display size in the primarytask data of Logan's (1978) consistent-mapping search task. It may be important that in the present experiment (and in Logan's), both the targets and the distractors in the consistent-mapping condition were letters. A complete independence between RT and display size is achieved most readily when the targets and distractors are categorically distinct (e.g., letters vs. digits) (Cheng, 1985; Shiffrin \& Schneider, 1977).

The changes in search RT that occurred between Day 5 and Day 6 provide additional evidence that stimulusresponse mapping influenced search performance. As is evident in Figure 1, both mean RT and the display-size effect increased substantially when a varied-mapping task followed five sessions of consistent-mapping training. On Day 6, search RT was actually slower for the subjects who had switched from consistent mapping than for the subjects who had performed varied mapping on Days 1-5. The present results are consistent with Shiffrin and Schneider's (1977) demonstration that search performance deteriorates when target and distractor sets are reversed following training under consistent-mapping conditions. The present data do not indicate whether the increase in search RT associated with the switch from consistent to varied mapping was due to the change in stimulusresponse mapping per se (independent of particular stimuli) or to the disruption of recognition and response processes for specific stimulus sets. The increase in search
RT on Day 6 does provide evidence, however, that the nature of the search process differed for the two mapping conditions on Days 1-5, in that consistent-mapping search was not easily transferable to a varied-mapping task.

The increases in visual-search RT associated with the presence of the tone, and the effects of SOA in the searchRT data, suggest that the subjects were not completely successful in keeping visual-search and tone-detection performance separate. Increases in search RT associated with tone presence also occurred in the Logan (1978) and Madden (1986) experiments, and Kantowitz (1985) noted that the ideal condition of complete separability between primary and secondary tasks is rarely obtained. However, the effects of SOA in the visual-search data were, for the most part, restricted to the varied-mapping condition and to Day 1 . In addition, the IRI between the visual and the tone responses was primarily a linear function of SOA and possessed a slope near 1.0, which is consistent with task separability (Kahneman, 1973, chap. 9). Although significant deviations from linearity were present in the IRI values, the data indicate that the subjects were able to perform the visual-search and tone-detection tasks relatively independently, and that the interaction that did occur did not lead to a systematic relation between the visual and tone responses.

\section{Secondary-Task Performance}

The changes in tone RT that occurred as a function of the primary-task conditions demonstrated that both display size and stimulus-response mapping influenced the attentional demands of the search. On Days 1-5, tone RT was slower for four-item displays than for two-item displays, and this display-size effect was more pronounced in the varied-mapping condition than in the consistentmapping condition. The display-size effect was significant within each mapping condition, however, and the simple main effect of mapping was not significant for either display size on Days 1-5. Thus, as was the case in the primary-task, consistent mapping was associated with a reduction in magnitude, rather than with a complete elimination, of the effects of processing load. Although previous dual-task studies have reported substantial differences in the attentional demands of variedand consistent-mapping conditions (e.g., Schneider \& Fisk, 1982), the present data indicate that such differences are not inevitable, at least over the first thousand trials of training. Evidence from other forms of visual search has also suggested that consistent-mapping search does require attentional capacity (Fisher, Duffy, Young, \& Pollatsek, 1988; Hoffman, Nelson, \& Houck, 1983).

Changes in the amount, as opposed to the duration, of the attentional demands of the search task are defined by changes in the height and breadth, respectively, of the curve relating tone RT to the SOA between the tone and the display. On Days 1-5, the peak of the SOA curve for both display sizes occurred $100 \mathrm{msec}$ following display onset, and the height of the SOA curve at that point was significantly greater for four-item displays than for twoitem displays. On Day 1, the breadth of the SOA curve 
also increased as display size increased. Subsequent to Day 1, the breadth of the SOA curves for the two- and four-item displays were equivalent, but the simple main effect of display size remained significant at the 100 -msec SOA, and there was no significant change in the shape of the SOA curve across Days 2-5 (see Table 1). Switching from consistent to varied mapping on Day 6 led both to a significant increase in the magnitude of the displaysize effect in tone RT, and to a change in the SOA curve. Both the height and breadth of the SOA curve for the fouritem displays increased on Day 6; tone RT for the twoitem displays was relatively unaffected (see Figure 3).

The most important aspect of the tone-RT data is the significant increase in the height of the SOA curve as a function of display size. The presence of this increase on Days 1-5 confirms Madden's (1986) results but is inconsistent with Logan's (1978) findings. The difference between Logan's and Madden's results cannot be attributed either to stimulus-response mapping or to the amount of training, because there was no significant change in the shape of the SOA curve as a function of consistent, as opposed to varied, mapping across Days 1-5. The increase in the height and breadth of the SOA curve on Day 6, following the switch from consistent to varied mapping, demonstrates that there were conditions under which the nature of the stimulus-response mapping influenced the amount and duration of attentional demands. The secondary-task data resemble the pattern of the search RTs, in that switching from consistent to varied mapping on Day 6 had a more pronounced effect than consistentmapping training on Days 1-5.

Because the amount of attentional demand increased as a function of display size in the present experiment, the data indicate that the comparison between target and display items is a limited-capacity process. In fact, the effect of display size was more clearly evident in the amount, rather than in the duration, of attentional demand. After Day 1, tone RT for both display sizes declined below the level of the -400 -msec SOA by $400 \mathrm{msec}$ following display onset. Because the peak of the SOA curve occurred at the same point (100 msec after display onset) for both display sizes, the present data are most compatible with a limited-capacity parallel model of search performance, in which the target-display comparisons are made simultaneously (e.g., Fisher et al., 1988). A limitedcapacity serial model could also be accommodated to the present results, however, by assuming specific influences of a bookkeeping operation (independent of the comparison process) on the SOA curve (see Logan, 1978).

The present data suggest that the increase in attentional demands as a function of display size is a reliable phenomenon, and is not modified substantially (over the first thousand trials of practice) by consistent-mapping training. Relatively minor methodological differences remain between the Logan (1978) experiment and the consistentmapping condition of the present experiment. Logan used the letters $\mathrm{A}$ and $\mathrm{V}$ as targets, for example (rather than
F and G), and used displays of 4, 8, and 12 letters (rather than 2 and 4 letters). Whether these or other design features are responsible for the increase in the height of the SOA curve as a function of display size remains to be determined. A more theory-driven approach would be to investigate whether conditions that facilitate the reduction of display-size effects under consistent-mapping conditions (e.g., letter/digit distinction between target and distractor items) also reduce the amount and duration of attentional demands during visual search.

\section{REFERENCES}

Atkinson, R. C., Holmgren, J. E., Juola, J. F. (1969). Processing time as influenced by the number of elements in a visual display. Perception \& Psychophysics, 6, 321-326.

Cheng, P. W. (1985). Restructuring versus automaticity: Altemative account of skill acquisition. Psychological Review, 92, 414-423.

Duncan, J. (1980). The demonstration of capacity limitation. Cognitive Psychology, 12, 75-96.

EsTES, W. K. (1972). Interactions of signal and background variables in visual processing. Perception \& Psychophysics, 12, 278-286.

Fisher, D. L., Duffy, S. A., Young, C., Pollatsek, A. (1988). Understanding the central processing limit in consistent-mapping visual search tasks. Journal of Experimental Psychology: Human Perception \& Performance, 14, 253-266.

GAMES, P. A. (1977). An improved $t$ table for simultaneous control on $g$ contrasts. Journal of the American Statistical Association, 72, 359.

GARDNER, G. T. (1973). Evidence for independent parallel channels in tachistoscopic perception. Cognitive Psychology, 4, 130-155.

Hoffman, J. E., Nelson, B., Houck, M. R. (1983). The role of attentional resources in automatic detection. Cognitive Psychology, 51, 379-410.

Kahneman, D. (1973). Attention and effort. Englewood Cliffs, NJ: Prentice-Hall.

KANTowTtz, B. H. (1985). Channels and stages in human information processing: A limited analysis of theory and methodology. Joumal of Mathematical Psychology, 29, 135-174.

KERR, B. (1973). Processing demands during mental operations. Memory \& Cognition, 1, 401-412.

LoGAN, G. D. (1976). Converging evidence for automatic perceptual processing in visual search. Canadian Journal of Psychology, 30, 193-200.

LogaN, G. D. (1978). Attention demands of visual search. Memory \& Cognition, 6, 446-453.

MADDEN, D. J. (1986). Adult age differences in the attentional capacity demands of visual search. Cognitive Development, 1, 335-363.

Rumelhart, D. E. (1970). A multicomponent theory of the perception of briefly exposed visual displays. Journal of Mathematical Psychology, 7, 191-218.

SchneIder, W., Dumais, S. T., \& Shiffrin, R. M. (1984). Automatic and control processing and attention. In $\mathbf{R}$. Parasuraman \& D. R. Davis (Eds.), Varieties of attention (pp. 1-27). Orlando, FL: Academic Press.

SchneIder, W., \& Fisk, A. D. (1982). Concurrent automatic and controlled visual search: Can processing occur without resource cost? Journal of Experimental Psychology: Learning, Memory, \& Cognition, 8, 261-278.

Shiffrin, R. M., \& SCHNEIDER, W. (1977). Controlled and automatic human information processing: II. Perceptual learning, automatic attending, and a general theory. Psychological Review, 84, 127-190.

Wickens, C. D. (1984). Processing resources in attention. In R. Parasuraman \& D. R. Davies (Eds.), Varieties of attention (pp. 63 102). Orlando, FL: Academic Press.

(Manuscript received September 19, 1988; revision accepted for publication December 5,1988 .) 